\title{
Predictors of post-partum family planning uptake in Webuye Hospital, western Kenya
}

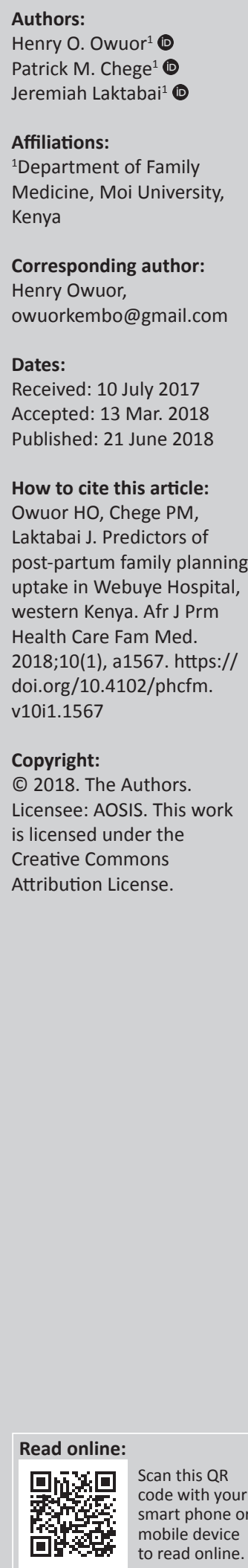

Background: A short inter-pregnancy interval increases the risk for maternal and neonatal deaths in addition to other pregnancy complications including: preterm delivery, low birth weight, anaemia and premature rupture of membranes. However, only one half of Kenyan women, who have no desire to conceive immediately after birth, are using contraception one year after delivery.

Aim: The aim of this study was to determine the predictors of uptake of post-partum family planning (PPFP).

Setting: The study was conducted among post-partum women accompanying their children for their first measles vaccination at Webuye County Hospital (WCH), in western Kenya.

Methods: This was a cross-sectional study involving 259 randomly sampled post-partum women, accompanying their children for their first measles vaccination. A structured, interviewer-administered questionnaire was used to collect data. Logistic regression was used to identify correlates of PPFP uptake.

Results: The uptake of PPFP among women at 9 months post-partum at WCH was found to be $78.4 \% \pm 5.0 \%$. The odds of PPFP uptake among women living with their sexual partners was $88.2 \%$ less than among those not living with their partners with the true population effect between $97 \%$ and $51 \%(\mathrm{OR}=0.118 ; 95 \% \mathrm{CI}$ : 0.028-0.494; $p=0.003)$.

Conclusions: Not living with her sexual partner in the same house is the key predictor of a woman's PPFP uptake in WCH. This study recommends that any programme aimed at improving post-partum contraceptive use in $\mathrm{WCH}$ should target women who live with their partners in the same house.

\section{Introduction}

Closely spaced pregnancies within the first year in the post-partum period are the riskiest for mother and baby, resulting in increased risks for adverse outcomes such as preterm deliveries, low birth weight and small for gestational age. ${ }^{1}$ Other risks associated with short inter-pregnancy intervals include neonatal death, maternal death, anaemia and premature rupture of membranes..$^{1,2}$ The risk of child mortality is highest for very short birth-to-pregnancy intervals ( $<12$ months) such that if all couples waited 24 months to conceive again, under-five mortality would decrease by $13 \%$, and if couples waited 36 months, the decrease would be $25 \% .{ }^{3}$ Family planning (FP) can avert more than $30 \%$ of maternal deaths and $10 \%$ of child mortality if couples space their pregnancies more than 2 years apart. ${ }^{4}$ Family planning is, therefore, recognised globally as a key life-saving intervention for mothers and their children. ${ }^{5}$

The prevention of unintended pregnancy and prevention of closely spaced pregnancies especially in the first 12 months following childbirth, a practice christened post-partum family planning (PPFP), should be an integral part of an existing maternal and child health and FP programme. ${ }^{6}$ The continuum of points of contact within the health care system that can provide opportunities for provision of integrated PPFP services include during pregnancy, labour and delivery, pre-discharge (0-48 hours), post-partum and during infant care from six weeks through 12 months. ${ }^{6,7}$

There is a high unmet need for FP among post-partum women. It is estimated that 222 million women in lower-income regions of the world want to avoid a pregnancy, but they use either a low-efficacy family-planning method or no method at all. ${ }^{8}$ According to an analysis of demographic and health survey data from 27 countries, $95 \%$ of women who are $0-12$ months post-partum wanted to avoid a pregnancy in the next 24 months but $70 \%$ of them were not using 
any form of contraception. ${ }^{9,10}$ In Kenya, a study reported that $36 \%$ of post-partum women had an unmet need for FP to prevent births and $48 \%$ had an unmet need for birth spacing with an overall post-partum unmet need of $46 \%{ }^{11}$ This unmet need for FP among post-partum women nearly triples the $18 \%$ unmet need among married women in the country as documented by the 2014 Kenya Demographic Health Survey (KDHS). ${ }^{12}$

Post-partum family planning uptake remains low in Kenya and in Bungoma County in western Kenya in particular.11,12 This low uptake of PPFP increases the risk of unplanned early pregnancies, pregnancy losses, low birth weight, preterm deliveries and maternal and neonatal mortality even among mothers who have had multiple contacts with health facilities for other reasons other than FP. This is evidenced by the high infant and child mortality in Kenya, that is, 39 and 52 deaths per 1000 births, respectively. ${ }^{12}$ This study's objective was, therefore, to determine the predictors of uptake of PPFP among post-partum women escorting their children for the first measles vaccination at Webuye County Hospital (WCH), western Kenya, so as to understand the potential barriers and facilitators of PPFP uptake. Knowledge of barriers and facilitators of PPFP will be useful in modifying practice among the health care workers who provide PPFP services at the maternal, neonatal and child health $(\mathrm{MNCH})$ clinics in $\mathrm{WCH}$ so as to increase PPFP uptake in the facility.

\section{Research methods and designs Study design}

A cross-sectional study design was used to conduct the study.

\section{Setting}

Webuye County Hospital is a district hospital in the western region of Kenya with a catchment population of 98494 people and 21669 women of reproductive age (15-49 years) as stated in its annual operating plan for 2015-2016 financial year. It provides both basic and emergency obstetric and new-born care (BEmONC and CEmONC) services in addition to antenatal care (ANC), postnatal care (PNC) and child wellness clinic (CWC) for immunisations. There are about 1700 new and 4000 revisits to the ANC, and an average of 3000 deliveries annually.

\section{Study population and sampling strategy}

The target population was post-partum women attending child immunisation clinics at Webuye Hospital. A modified systematic random sampling method was utilised to recruit study participants as there was no formal booking record at the hospital's child wellness or immunisation clinic for mothers accompanying their babies for the nine-month measles vaccine from which to construct a sampling frame.

\section{Sample size determination}

The sample size for the study was determined using the formula for estimation of single population proportion with the assumption of $95 \%$ confidence level, margin of error of $5 \%$ and expected prevalence of PPFP in Kenya of 51.1\%. ${ }^{11}$ To compensate for non-response, an additional $10 \%$ were sampled. This study, therefore, recruited 259 study participants.

\section{Inclusion and exclusion criteria}

All women who brought their children for their first measles vaccination before a year had lapsed since delivery, and consented to participate in the study, were eligible for recruitment. By this time, the mother had already had multiple contacts with the health care system, and because of weaning of the child, the protection conferred by lactational amenorrhea method (LAM) had waned. Women who attended the immunisation clinic for other vaccinations apart from the first measles vaccine, those who came for the first measles vaccine but after one ear from delivery women who were not the biological mothers of the children brought for the first measles vaccine before the first year and those who were not fit to respond adequately to questions asked owing to either the health condition of the mother or that of the child were excluded from the study.

\section{Pretesting the research instruments}

A pretest was conducted in a different hospital before the commencement of the main study in order to establish reliability and validity of data collection instruments and research procedures.

\section{Data collection}

A pretested, structured, interviewer-administered questionnaire was administered to the study participants by a trained research assistant. The filled questionnaires were checked daily for completeness, then coded and the data compiled in an excel database.

\section{Data analysis}

The database was cleaned and the data exported to SPSS-IBM version 20 for analysis. Descriptive statistics were used to summarise the data. Univariate regression was used to test any associations and to identify significant determinants of PPFP uptake. Multiple logistic regression models were then used to test any significant associations between the predictor factors and uptake of PPFP methods because the outcome data collected were categorical or binary.

\section{Ethical considerations}

This study was approved by the Moi Teaching and Referral Hospital's Institutional Research and Ethics Committee (IREC) and was granted a formal approval number FAN: IREC 1663 on 30 June 2016.

\section{Results}

A total of 259 women were enrolled in the study (see Table 1). 
TABLE 1: Demographic characteristics.

\begin{tabular}{|c|c|}
\hline Variable & Descriptive statistic \\
\hline Age & $27.1 \pm 5.8$ years \\
\hline \multicolumn{2}{|l|}{ Age group } \\
\hline $15-24$ & $37.8 \%$ \\
\hline $25-34$ & $48.3 \%$ \\
\hline $35-44$ & $13.5 \%$ \\
\hline$<15$ and $>44$ & $0.4 \%$ \\
\hline \multicolumn{2}{|l|}{ Marital status } \\
\hline Married & $86.9 \%$ \\
\hline Single & $12.0 \%$ \\
\hline Widow or separated or divorced & $1.2 \%$ \\
\hline Years of formal education & $10.3 \pm 3.3$ years \\
\hline None & $0.4 \%$ \\
\hline Primary (1-8) & $35.9 \%$ \\
\hline Secondary (9-12) & $42.9 \%$ \\
\hline Tertiary (> 12) & $20.8 \%$ \\
\hline Total number of pregnancies & $2.6 \pm 1.7$ pregnancies \\
\hline $1-4$ & $86.1 \%$ \\
\hline$>4$ & $13.9 \%$ \\
\hline Living children & $2.5 \pm 1.6$ children \\
\hline Male & $1.2 \pm 1.1$ \\
\hline Female & $1.3 \pm 1.2$ \\
\hline
\end{tabular}

TABLE 2: Post-partum family planning utilisation in Webuye County Hospital.

\begin{tabular}{lc}
\hline Variable & Descriptive statistic \\
\hline Current FP utilisation & $78.4 \%$ \\
Planning to use if not on FP & $60 \%$ \\
Barriers to using FP & \\
Social barriers & $13.7 \%$ \\
Side effects & $22.7 \%$ \\
Others & $63.6 \%$ \\
Method planned to use & \\
Hormonal contraception \pm barrier methods & $48.5 \%$ \\
Long-acting reversible methods & $24.2 \%$ \\
Permanent methods & $3.0 \%$ \\
Other & $24.3 \%$ \\
Duration to uptake of FP & \\
0-3 months & $81.8 \%$ \\
$>3$ months & $6.1 \%$ \\
Do not know & $12.1 \%$ \\
Current FP choice & \\
Hormonal contraception \pm barrier methods & $63.2 \%$ \\
Long-acting reversible methods & $33.8 \%$ \\
Permanent methods & $2.5 \%$ \\
Other & $0.5 \%$ \\
Women's preference & $96.9 \%$ \\
\hline
\end{tabular}

FP, family planning.

Majority of those who desired future conception (65.3\%) were planning to wait for an average of 4 years, whereas $30.9 \%$ reported to have reached the end of their obstetric careers. More than half $(57.9 \%)$ of all the women sampled reported past use of an FP method with $22.7 \%$ of these being on long-acting reversible contraceptives (LARCs) whilst the rest were on the less effective natural, hormonal or barrier FP methods. The main reason given by the mothers for unplanned pregnancies was non-use of FP $(76.3 \%)$.

Contact with a formal health facility during the latest pregnancy was fairly high with $99.6 \%$ attending an average of $4 \pm 1.4$ ANC clinic visits, $80.7 \%$ delivering in a health facility and all the women (100\%) attending the CWC. Utilisation of PNC services was; however, low at $31.7 \%$. Of those attending ANC, only $15 \%$ were counselled on FP. Counselling rates were higher at delivery (74.2\%), at PNC (72.6\%) and at CWC (90.3\%). Male partner involvement was high: $80 \%$ lived together with their partners and $81.7 \%$ had discussed FP. Of the women on FP, $89 \%$ reported that their partners know they are on FP; $86 \%$ of which approve the FP choice of their partners and $77 \%$ gave some form of support for the woman to get her FP of choice.

The uptake of PPFP among women at 9 months post-partum at Webuye Hospital is $78.4 \% \pm 5.0 \%$, and $33.8 \% \pm 6.5 \%$ of these women are on LARCs. Three-fifths of the women who are not on PPFP are planning to have a contraceptive method (Table 2).

On univariate logistic regression, the following factors were found to have significant association with PPFP uptake in Webuye Hospital:

- age $(p=0.002)$

- marital status $(p=0.001)$

- total number of previous pregnancies $(p=0.024)$

- number of living children (0.011)

- having plans for additional children $(p=0.018)$

- previous FP use before the latest pregnancy $(p<0.001)$

- provision of FP services during the child wellness or immunisation clinics ( $p=0.023$ )

- the woman living together with the partner in the same house $(p<0.001)$

- discussing FP with the partner $(p<0.001)$

- the male partner's approval of FP $(p=0.003)$

- any support offered by the male partner $(p<0.001)$.

However, only living with the partner $(p=0.003)$ remained statistically significant on multiple logistic regression as shown in Table 4. The odds of PPFP uptake among women living with their sexual partners were $88.2 \%$ less than among those not living with their partners (i.e. those not living with their partners are 8.5 times more likely to use PPFP than those living with their partners) with the true population effect between $51 \%$ and $97 \%$. Therefore, women who live with their partners in the same house are less likely to use PPFP. There was a significant increase in current FP use to the FP prevalence before the last pregnancy $(p<0.001)$.

\section{Discussion}

\section{Key findings}

The uptake of PPFP among women at 9 months post-partum at Webuye Hospital is $78.4 \% \pm 5.0 \%$, and $33.8 \% \pm 6.5 \%$ of these women are on LARCs. There was a significant increase in current FP use to the FP prevalence before the last pregnancy $(p<0.001)$. Living with the sexual partner was the only independent variable that was significantly associated with PPFP uptake (OR =0.118; 95\% CI: 0.028-0.494; $p=0.003$ ). That is to say, the odds of PPFP uptake among women living 
TABLE 3: Univariate logistic regression of predictive factors on post-partum family planning use in Webuye County Hospital.

\begin{tabular}{|c|c|c|c|c|c|c|}
\hline S. No. & Variable & $\beta$ & s.e. & Sig. & OR $\left(e^{\beta}\right)$ & $95 \% \mathrm{Cl}$ for $\mathrm{OR}$ \\
\hline 1. & Age & 0.090 & 0.029 & 0.002 & 1.094 & $1.033-1.159$ \\
\hline 2. & Marital status & -2.085 & 0.410 & 0.001 & 0.124 & $0.056-0.278$ \\
\hline 3. & Education (YFE) & 0.029 & 0.045 & 0.527 & 1.029 & $0.941-1.125$ \\
\hline \multirow[t]{2}{*}{4.} & Total pregnancies & 0.241 & 0.106 & 0.024 & 1.272 & $1.032-1.567$ \\
\hline & $>4$ & -0.609 & 0.508 & 0.230 & 0.544 & $0.201-1.471$ \\
\hline \multirow[t]{3}{*}{5.} & Number of living children & 0.301 & 0.119 & 0.011 & 1.351 & $1.071-1.705$ \\
\hline & Male & 0.266 & 0.156 & 0.088 & 1.305 & $0.961-1.773$ \\
\hline & Female & 0.319 & 0.155 & 0.039 & 1.376 & $1.016-1.863$ \\
\hline \multirow[t]{3}{*}{6.} & Plans for another child & - & - & 0.060 & - & - \\
\hline & Yes & -0.902 & 0.381 & 0.018 & 0.406 & $0.192-0.856$ \\
\hline & Maybe or do not know & -0.560 & 0.860 & 0.515 & 0.571 & $0.106-3.802$ \\
\hline 7. & Number of future children & -0.336 & 0.237 & 0.156 & 0.715 & $0.449-1.136$ \\
\hline 8. & Duration to wait & -0.094 & 0.102 & 0.359 & 0.911 & $0.746-1.112$ \\
\hline 9. & Previous FP use & 1.367 & 0.322 & $<0.001$ & 3.925 & $2.089-7.374$ \\
\hline 10. & ANC attendance & -19.925 & 40193 & 1.000 & 0.000 & 0.000 \\
\hline 12. & $\mathrm{ANC}$ at a $\mathrm{PH}$ & - & - & 0.844 & - & - \\
\hline 13. & Delivery in a $\mathrm{PH}$ & - & - & 0.816 & - & - \\
\hline 14. & PNC attendance & 0.077 & 0.327 & 0.813 & 1.081 & $0.569-2.052$ \\
\hline 15. & FP counselling at ANC & -0.260 & 0.402 & 0.518 & 0.771 & $0.350-1.697$ \\
\hline 16. & FP services at delivery & 0.386 & 0.359 & 0.281 & 1.472 & $0.729-2.972$ \\
\hline 17. & FP services during PNC & 0.886 & 0.550 & 0.107 & 2.424 & $0.825-7.125$ \\
\hline 18. & FP services during CWC & 1.002 & 0.440 & 0.023 & 2.725 & $1.150-6.465$ \\
\hline 19. & Counselling on spacing & -0.219 & 0.367 & 0.551 & 0.803 & $0.391-1.649$ \\
\hline 20. & Counselling on availability of FP & 0.499 & 0.452 & 0.269 & 1.647 & $0.680-3.990$ \\
\hline 21. & Living with the partner & 2.057 & 0.347 & $<0.001$ & 7.826 & $3.964-15.452$ \\
\hline 22. & Discussing with partner & 1.959 & 0.354 & $<0.001$ & 7.092 & $3.542-14.200$ \\
\hline 23. & Approval by partner & 1.410 & 0.468 & 0.003 & 4.097 & $1.637-10.253$ \\
\hline 24. & Support by partner & 1.740 & 0.387 & $<0.001$ & 5.700 & $2.670-12.166$ \\
\hline
\end{tabular}

FP, family planning; ANC, antenatal care; PNC, postnatal care; CWC, child wellness clinic; $\beta$, the coefficient for the constant; s.e., the standard error around the coefficient for the constant; Sig., $p$-value; $\mathrm{OR}\left(\mathrm{e}^{\mathrm{\beta}}\right)$, the degree of association between the outcome and the predictor variables; $\mathrm{Cl}$, confidence interval; $\mathrm{YFE}$, years of formal education; PH, public hospital; $\mathrm{S}$.No. , serial number.

TABLE 4: Multiple logistic regression of predictors of post-partum family planning use in Webuye County Hospital.

\begin{tabular}{|c|c|c|c|c|c|}
\hline Variable & $\beta$ & s.e. & Sig. & $\mathrm{OR}\left(\mathrm{e}^{\beta}\right)$ & $95 \% \mathrm{Cl}$ for $\mathrm{OR}$ \\
\hline Age & -0.010 & 0.063 & 0.869 & 0.990 & $0.875-1.119$ \\
\hline Marital status & & & 0.014 & & \\
\hline Single & -22.327 & 21672.2 & 0.999 & 0.000 & 0.000 \\
\hline Separated or divorced & -18.008 & 21672.2 & 0.999 & 0.000 & 0.000 \\
\hline Total pregnancies & 0.005 & 0.556 & 0.993 & 1.005 & $0.338-2.989$ \\
\hline Number of living children & -0.107 & 0.612 & 0.861 & 0.898 & $0.270-2.983$ \\
\hline Female children alive & 0.111 & 0.343 & 0.746 & 1.118 & $0.570-2.190$ \\
\hline Yes & -18.020 & 15122.1 & 0.999 & 0.000 & 0.000 \\
\hline Maybe or I do not know & -18.610 & 15122.1 & 0.999 & 0.000 & 0.000 \\
\hline $\mathrm{FPb} 4(1)$ & -0.583 & 0.598 & 0.330 & 0.558 & $0.173-1.803$ \\
\hline CWCFP (1) & -0.007 & 0.870 & 0.993 & 0.993 & $0.181-5.460$ \\
\hline Live with partner & -2.135 & 0.730 & 0.003 & 0.118 & $0.028-0.494$ \\
\hline Discussed with partner & -0.314 & 0.857 & 0.714 & 0.731 & $0.136-3.915$ \\
\hline Partner approval & -1.975 & 1.098 & 0.072 & 0.139 & $0.016-1.194$ \\
\hline
\end{tabular}

FP, family planning; CWCFP, child wellness clinic family planning; $\beta$, the coefficient for the constant; s.e., the standard error around the coefficient for the constant; Sig., $p$-value; OR( $\mathrm{e}^{\beta}$ ), the degree of association between the outcome and the predictor variables; $\mathrm{Cl}$, confidence interval.

with their sexual partners was $88.2 \%$ less than among those not living with their partners (i.e. those not living with their partners are 8.5 times more likely to use PPFP than those living with their partners) with the true population effect between $97 \%$ and $51 \%$.

\section{Discussion of key findings}

The level of current use of PPFP (contraceptive prevalence rate) among women taking their children for measles vaccination at 9 months in $\mathrm{WCH}$ is much higher than the national contraceptive prevalence rate (CPR) that is $58 \% .{ }^{12}$ The CPR for Bungoma County and western region is $55.5 \%$ and $58.6 \%$, respectively. ${ }^{12}$ In addition, the uptake of the LARCs in this study (33.8\%) is also higher than the national average of $13.3 \%{ }^{12}$ The prevalence of LARCs use in Bungoma County and western region is $12.6 \%$ and $16.5 \%$, respectively. ${ }^{12}$ The higher prevalence rate or uptake of FP in the sampled population may be explained by the differing characteristics of the sample population and the high health service contact it has compared to other women in Bungoma County and the 
western region in general. In addition, this was a facilitybased study, whereas the KDHS was a community-based study.

The literacy levels and the average age of the sample population may be particularly contributive to the higher prevalence or uptake of FP than in the general population. Level of education, socio-economic status and age of the woman were identified as factors that influence the intention to use PPFP in Nigeria. ${ }^{13,14}$ Higher levels of education result in a better understanding of the available modern contraceptive methods, the benefits of fertility regulation, awareness of the side effects of contraceptive methods and preference for the most convenient ones. ${ }^{15}$ PPFP uptake is higher among women in the 20-29 age categories because they have not finished child-bearing. ${ }^{13}$ In addition, the women in this age category have a higher intention to use a contraceptive method. ${ }^{13}$ In the KDHS, $42.7 \%$ of women had at least secondary education, whereas $37.2 \%$ were below 25 years of age. ${ }^{12}$

The significant increase in current FP use to the FP prevalence before the latest pregnancy may be explained by the higher counselling rates and FP service provision during the multiple interactions with the health facility, for example, during MNCH clinic visits. ${ }^{16,17}$

The only factor that was predictive of increased PPFP uptake was not living with the sexual partner in the same house. Women who lived with their partners were less likely to use FP than those who do not. Men often make the final decision about FP use, especially in traditional patriarchal societies like in Kenya. ${ }^{15,18}$ Women who live with their sexual partners may be highly dependent on their spouses for approval of modern contraceptive use. On the contrary, women who do not live with their sexual partners may be under no obligation to seek approval from any one concerning contraceptive use. Thus, partner's non-approval may be a major reason for non-use of modern contraceptive among the women who live with their sexual partners in the same house. ${ }^{19}$ Studies have shown that male dominated decisionmaking about fertility preference is associated with lower use of contraceptives. ${ }^{20,21,22,23,24}$ On the contrary, other studies have revealed that women who live or cohabit with a partner use more FP services than those who live separately from their partners. ${ }^{25}$ This has been linked to the support the women get from their partners.

The lack of association between PPFP uptake and ANC attendance may be attributed to the timelag between the counselling, the need for the contraceptive, ${ }^{26}$ and the absence of provision of FP information and services during ANC. ${ }^{27}$ Other studies have found that prenatal contraceptive counselling may benefit women who are economically disadvantaged and with a lower education level than those who are more educated, suggesting an interaction with education level of the women. ${ }^{28}$ The lack of association between facility delivery and PPFP uptake in this study could be because of lack of simultaneous provision of FP counselling and FP method to the woman before discharge from the hospital.

Other factors that have been associated with the uptake of FP like age, the number of living children or previous pregnancies, previous FP use, plans for additional children, discussing FP with the partner and partner's approval and support were not associated with PPFP uptake in this population. The lack of association between these factors and PPFP uptake may be masked by the effect of integrating FP services into the $\mathrm{MNCH}$ services, the high utilisation of health services in this population and the demographic characteristics.

\section{Strengths and limitations}

Recall bias and social desirability bias are all inherent weaknesses of cross-sectional studies. These were; however, minimised by assuring the study participants of confidentiality and interviewing them in private areas within the clinic in the absence of a third party. The social distance was also minimised. The study was conducted in a single facility, but findings are generalisable to other facilities in the region or to the population in this geographical area because the measles vaccine coverage in Bungoma is quite high at $84.3 \% .^{12}$

\section{Implications or recommendations}

With these findings, the study recommends that programmes aimed at enhancing post-partum contraceptive use in $\mathrm{WCH}$ should target women who live with their partners in the same house, as they are less likely to use PPFP. Increasing reproductive health education among postpartum women who live with their partners in the same house will significantly improve the uptake of PPFP in $\mathrm{WCH}$. This study further recommends that the national and/or county government and development partners to sponsor training of FP providers, $\mathrm{MCH}$ nurses and other care providers on the role of the marital status of the postpartum woman and her living with her partner factors to bolster PPFP use in $\mathrm{WCH}$.

\section{Conclusion}

The PPFP uptake in WCH is higher than both the national and county contraceptive prevalence rates. Not living with the sexual partner in the same house is the key predictor of a woman's PPFP uptake in WCH. The observed integration of FP with MNCH services should be strengthened as this may have contributed to the increase in FP use at 9 months postpartum compared to FP use before the latest pregnancy.

\section{Acknowledgements}

The authors wish to acknowledge Moi University for providing the ethical clearance and the medical superintendent of Webuye County Hospital and the in-charge of Child Wellness 
Clinic for granting the permission to conduct this study. They also acknowledge the reviewers of the African Journal of Primary Healthcare E Family Medicine for reviewing the draft manuscript.

\section{Competing interests}

The authors declare that they have no financial or personal relationships that may have inappropriately influenced them in writing this article.

\section{Authors' contributions}

H.O.O. (Resident) made substantial contributions to the conception, study design, acquisition of data, data analysis and interpretation for his thesis for a Master of Medicine in Family Medicine. P.M.C. and J.L. (Family Medicine Lecturers) drafted the article, revising it critically for important intellectual content, and gave the final approval of the submitted version.

\section{References}

1. DaVanzo J, Hale L, Razzaque A, et al. Effects of interpregnancy interval and outcome of the preceding pregnancy on pregnancy outcomes in Matlab, Bangladesh. BJOG. 2007;114(9):1079-1087. https://doi.org/10.1111/j.14710528.2007.01338.x

2. Conde-Agudelo A, Belizán JM, Lammers C. Maternal-perinatal morbidity and mortality associated with adolescent pregnancy in Latin America: Cross-sectional study. Am Obstet Gynecol. 2005;192:342-349. https://doi.org/10.1016/j.ajog.2004.10.593

3. Rutstein SO. Further evidence of the effects of preceding birth intervals on neonatal, infant and under-five-years mortality and nutritional status in developing countries: Evidence from the demographic and health surveys. DHS Working Papers. Calverton, MD: Demographic and Health Research Division; 2008; p. 41

4. Cleland J, Bernstein S, Ezeh A, et al. Family planning: The unfinished agenda. Lancet 2006;368(9549):1810-1827. https://doi.org/10.1016/S0140-6736(06)69480-4

5. World Health Organization. Family planning: A health and development issue, a key intervention for the survival of women and children [homepage on the Internet]. 2012. [cited 2016 Feb 09]. Available from: http://www.who.int/ reproductivehealth/publications/family_planning/rhr_12_23/en/

6. World Health Organization. Programming strategies for postpartum family planning [homepage on the Internet]. 2013. [cited 2016 Feb 09]. Available from: http://www.who.int/reproductivehealth/publications/family_planning/ppfp strategies/en/

7. Vance $G$, Janowitz J, Chen $M$, et al. Integrating family planning messages into immunization services: A cluster-randomized trial in Ghana and Zambia. Health Policy Plan. 2014;29(3):359-366. https://doi.org/10.1093/heapol/czt022

8. Singh S, Darroch JE. Adding it up: Costs and benefits of contraceptive services Estimates for 2012 [homepage on the Internet]. New York: Guttmacher Institute and United Nationals Population Fund; 2012. [cited 2016 Feb 11]. Available from: http://www.guttmacher.org/pubs/AlU-2012-estimates.pdf

9. Ross JA, Winfrey WL. Contraceptive accessed use, intention to use and unmet need during the extended postpartum period. Int Fam Plan Perspect. 2001;27(1):20-27. https://doi.org/10.2307/2673801
10. Borda M, Winfrey W. Postpartum fertility and contraception: An analysis of findings from 17 countries [homepage on the Internet]. Baltimore, MD: Jhpiego; 2010. [cited 2016 Feb 09]. Available from: http://www.k4health.org/sites/ default/files/Winfrey_Borda_17countryanalysis.pdf

11. Pasha O, Goudar SS, Patel A. Postpartum contraceptive use and unmet need for family planning in five low-income countries. Reprod Health. 2015;12(2):S11. https://doi.org/10.1186/1742-4755-12-S2-S11

12. Kenya National Bureau of Statistics, Ministry of Health/Kenya, National AIDS Control Council/Kenya, Kenya Medical Research Institute, and National Council for Population and Development/Kenya. 2015. Kenya Demographic and Health Survey 2014 [homepage on the Internet]. Rockville, MD. [cited 2016 Feb 02]. Available from: http://dhsprogram.com/pubs/pdf/FR308/FR308.pdf

13. Idowu A, Deji SA, Ogunlaja O, et al. Determinants of intention to use post-partum family planning among women attending immunization clinic of a tertiary hospital in Nigeria. Am J Public Health Res. 2015;3(4):122-127.

14. Abrah P. Predictors of post-abortion family planning uptake in the New Juaben Municipality, Ghana. New Jubean Municipality, Ghana: KNUSTSpace institutional repository, College of Health Sciences; 2014.

15. Mekonnen W, Worku A. Determinants of low family planning use and high unmet need in Butajira District, South Central Ethiopia. Reprod Health. 2011;8:37. https://doi.org/10.1186/1742-4755-8-37

16. Akinlo A, Bisiriyu A, Esimai O. 2013. Influence of use of maternal health care on postpartum contraception in Nigeria. DHS Working Paper Series No. 92. Calverton, MD: ICF International.

17. K4Health. Maternal, infant and young child nutrition and family planning (MIYCNFP) integration toolkit. Baltimore, MD: Johns Hopkins University; 2015.

18. Yue K, O'Donnel C, Sparks PL. The effect of spousal communication on contraceptive use in Central Terai, Nepal. Patient Educ Couns. 2010;81(3):402408. https://doi.org/10.1016/j.pec.2010.07.018

19. Andi JR, Wamala R, Ocaya B, et al. Modern contraceptive use among women in Uganda: An analysis of trend and patterns (1995-2011). Afr Popul Stud. 2014;28(2):1009-1021. https://doi.org/10.11564/28-0-553

20. Mosha I, Ruben R, Kakoko D. Family planning decisions, perceptions and gender dynamics among couples in Mwanza, Tanzania: A qualitative study. BMC Public Health. 2013;13(1):523. https://doi.org/10.1186/1471-2458-13-523

21. Adugnaw B, Sibhatu B, Alemayehu A, et al. Men's knowledge and spousal communication about modern family planning methods in Ethiopia. Afr J Reprod Health. 2011;15(4):24-32.

22. Nattabi B, Li J, Thompson SC, et al. Family planning among people living with HIV in post-conflict Northern Uganda: A mixed methods study. Conflict Health. 2011;5(1):18. https://doi.org/10.1186/1752-1505-5-18

23. DeRose LF, Ezeh AC. Decision-making patterns and contraceptive use: Evidence from Uganda. Popul Res Policy Rev. 2010;29(3):423-439. https://doi.org/10.1007/ s11113-009-9151-8

24. Dudgeon MR, Inhorn MC. Men's influences on women's reproductive health: Medical anthropological perspectives. Soc Sci Med. 2004;59(7):1379-1395. https://doi.org/10.1016/j.socscimed.2003.11.035

25. Orach CG, Otim G, Aporomon JF, et al. Perceptions, attitude and use of family planning services in post conflict Gulu district, northern Uganda. Conflict Health. 2015;9:24. https://doi.org/10.1186/s13031-015-0050-9

26. Ayiasi RM, Muhumuza C, Bukenya J, et al. The effect of prenatal counselling on postpartum family planning use among early postpartum women in Masindi and Kiryandongo districts, Uganda. Pan Afr Med J. 2015;21:138. https://doi.org/ 10.11604/pamj.2015.21.138.7026

27. Hounton S, Winfrey W, Barros AJD, et al. Patterns and trends of postpartum family planning in Ethiopia, Malawi, and Nigeria: Evidence of missed opportunities for integration. Glob Health Action. 2015;8:10. https://doi.org/10.3402/gha. v8.29738

28. Hernandez LE, Sappenfield WM, Goodman D, et al. Is effective contraceptive use conceived prenatally in Florida? The association between prenatal contraceptive counseling and postpartum contraceptive use. Matern Child Health J. 2012;16(2):423-429. https://doi.org/10.1007/s10995-010-0738-9 